\title{
The Syntactic Structure of Modal Verbs in Chinese
}

\author{
Jingjing Cui \\ School of Applied English Studies, Shandong University of Finance \&Economics, Jinan, China
}

\begin{abstract}
This paper investigates the syntactic properties of modal verbs in Chinese. By comparing the differences between epistemic and root modal verbs, we try to get the syntactic properties of modal verbs. This paper makes modal verbs related to aspect markers and concludes that root modal verbs originate in ASPP and have complementary distribution with aspect markers; they take VP as their complement. Based on the two arguments that epistemic modal verbs cannot occur in nonassertive contexts and the asymmetry of negation of modal verbs this paper claims that epistemic modal verbs are in IP and move to the position of CP, and they have complementary distribution with nonassertive contexts; they select IP as their complement. The established proposal can adequately account for not only the succession of modal verbs but also some controversial issues.
\end{abstract}

Index Terms — root modal verbs, epistemic modal verbs, aspect markers, nonassertive contexts

\section{INTRODUCTION}

It is well noted that modal verbs in Chinese receive two distinct readings, traditionally termed epistemic and root. Epistemic modals are concerned with belief and attitude of the speaker, whereas root modals typically describe volition, ability, or permission according to Palmer (2001).

The distribution and the syntactic properties of the constructions in which these elements appear have been the most extensively discussed topics for a long time. Various proposals have been made to account for them. Though the previous studies have reached agreement that epistemic modal verbs and root modal verbs are merged at different level of insertion, which can explain the succession of modal verbs, there is still very little consensus among linguists as to the best way to characterize the difference between epistemic and root, especially two central while controversial facts (I), (II), as illustrated by (1) and (2).

(I) Compatibility between epistemic modal verbs and aspect markers ${ }^{1}$ or incompatibility between root (deontic and dynamic) modal verbs and aspect markers.

(II) Ability of root modal verbs to occur in nonassertive contexts or inability of epistemic modal verbs to occur in nonassertive contexts.

(1) a. Tamen keneng/yinggai ying-guo qiu.

"They might have won the ball."

b. *Tamen neng/keyi ying-guo qiu.

"*They can have won the ball."

(2) a. Ren weishenme hui si?

"Why will people die?"

b.*Ren weishenme keneng si?

"Why might people die?"

As for the differences between epistemic and root modal verbs, different linguists have different views, and various proposals are put forward. Picallo (1990) suggested the difference between epistemic and deontic modals is determined at the level of insertion (merge); epistemic modals are merged somewhere within the IP level, and roots (deontic), somewhere within the VP. McDowell (1987) claimed that it is LF that is relevant, with epistemic modals appearing in C at that level and roots (deontic) in VP. Brennan (1997) made a similar claim. Cormack \& Smith $(1997,1998)$ had modals merged as heads of discrete modal phrases within IP, but again derive their different semantic behaviors at LF.

The above accounts discuss that epistemic and deontic modal verbs are different from the syntactic perspectives. They can explain the succession of different modal verbs and the order of them. For instance, in the following sentence that "Ta keneng neng kaoshang daxue. (It is possible that he should enter the university)", "keneng" has an epistemic interpretation, while "neng" receives a deontic interpretation. "keneng" must occur before "neng", for epistemic and deontic modals are determined at the different levels of insertion (merge); epistemic modals are merged somewhere within the IP level, and roots (deontic), somewhere within the VP. So the order of the two kinds of modal verbs cannot change. This analysis can explain the order of multiple modal verbs. But the above analysis cannot explain other

\footnotetext{
1 There are two kinds of aspect markers. One is verbal aspectual markers; the other is the sentence-final aspectual particles. They occupy the different syntactic position. Verbal aspectual markers are in ASP, sentence-final aspectual particles are in C. So any sentence-final aspectual particles can occur with root modal verbs, while verbal aspectual markers cannot. In this paper, aspect markers mainly refer to verbal aspectual markers.
} 
phenomena. For example, why can modal verbs not co-occur with the aspect markers? What is the relationship between modal verbs and aspect markers?

\section{MOdAl Verbs AND ASPECT MARKeRS}

A. Verb Suffixes:-le, -guo, -zhe and Aspect Head: zai

$-L e,-g u o$ and $-z h e$ are different in span. -Le and -guo express perfective viewpoint, while -zhe expresses imperfective viewpoint. - Le spans the initial and final endpoints of an event, which means the actualization of a situation and presents it as a whole; the span of -guo extends beyond the final endpoint of a situation, which is in experiential sense and conveys a discontinuity with the present; -zhe presents a continuous and stable situation without respect to endpoints. Consider the following sentences:

(3) a. Zhangsan kan -guo/-zhe na ben shu.

"Zhangsan has read that book."

b. *Zhangsan kan na ben shu -guo/-zhe.

"Zhangsan has read that book."

We may conclude that aspectual markers - guo and -zhe in sentence (3) are bound morphemes that do not themselves act like verbs. Sentence (3) also illustrates the fact that aspectual markers in Chinese are required to follow the host verb immediately, with no intervening elements. This non-detachability of the three aspectual markers from their host verbs indicates that aspectual markers appear at the lexical level, not at the phrasal level.

Zai presents an internal interval of a durative situation, with a sense of progressiveness. Zai appears preceding the verb, and often co-occurs with the morpheme zheng and the sentence particle ne, while -le, -zhe, -guo occur after the verb. Aspect marker zai is different from aspect markers -le, -zhe and -guo. Consider the following sentences.

(4) Tamen zai youyong.

"They are swimming."

(5) * Tamen youyong zai.

"They are swimming."

(6) Tamen zai youyongci li youyong.

"They are swimming in the pool."

We may conclude that aspectual marker zai precedes the verb and take VP as complement, but it is not required to precede the verb immediately. An adjunct like youyongcili (in the pool) in (6) can occur between zai and the verb youyong (swim), which suggests that zai attaches at the phrasal level.

\section{B. The Relationship between Aspect Markers and Modal Verbs}

Since there are two kinds of aspect markers, one is the verb suffixes $-l e$, -zhe and -guo, the other is aspect head zai. What is the relationship between aspect markers and modal verbs? Consider the following sentences:

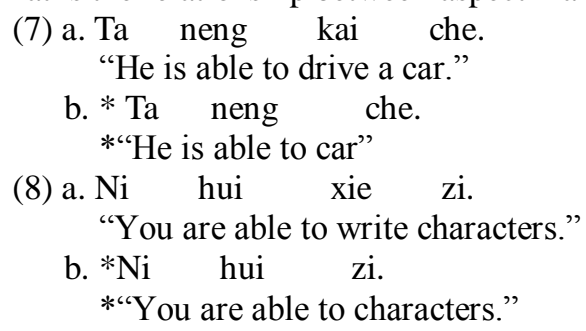

The above sentences show that modal verbs cannot themselves act like verbs that directly take NPs as complements; they must take VPs as their complements. This suggests that modal verbs attach at the phrasal level, not at the lexical level.

By comparing the above sentences with sentence (3), we may conclude that aspectual markers $-l e,-z h e$ and $-g u o$ are suffixes of verbs, they cannot themselves act like verbs, while modal verbs must take VP as their complement. They are all related to verbs. By comparing the above sentences with sentences (4-6), we also find that both aspect marker zai and modal verbs can precede the verbs and take VP as their complement.

To sum up, modal verbs and aspect markers are related to verbs. Aspect markers -le, -zhe and -guo are suffixes of verbs, so they cannot themselves act like verbs, while modal verbs and aspect marker -zai must take VPs as their complements. Since aspect marker -zai functions as ASP head, taking VP as complements headed by main verbs. Modal verbs are like aspect marker -zai. So we may assume that modal verbs also function as ASP head, taking VP complements headed by main verbs. That is to say, modal verbs and aspect marker -zai are the head of ASP, generating the AspP, with the VP in their scope. Sentences without modal verbs or aspect marker -zai may have the empty Aspect node functioning as the head that licenses the corresponding affix on the main verb. This would be treated by making $-l e(-g u o /-z h e)$ a base-generated verb affix, which moves to the next upper functional head. This is parallel to English verbs with $-e d$ or $-s$ moving to Tense node. Sentences with modal verbs may not allow aspect markers to occur. We may conclude that modal verbs have complementary distribution with aspect markers -le, -zhe and -guo. 


\section{Root Modal Verbs as AspP}

As we have argued, modal verbs and aspect marker zai are the head of ASP, generating the AspP, with the VP in their scope and they have complementary distribution with aspect markers -le, -zhe and -guo. So we may assume that both epistemic and deontic modals are determined at the same levels, they all originate in ASP and have complementary distribution with aspect markers. Now let's check up our assumption.

Since modal verbs are the head of ASP, aspect markers -zhe, -le and - guo are suffixes of verbs. Consider the following sentences:

(9) a. Tamen ying-guo/-le qiu.

"They have won the ball."

b. Tamen keneng/yinggai ying-guo/-le qiu.

"They might have won the ball."

c. *Tamen neng/keyi/hui ying-guo/-le qiu.

"*They can have won the ball."

Sentence(a) grammatical, for aspect marker -le is the suffix of verb mai, there is the empty Aspect node functioning as the head that licenses the corresponding affix on the main verb. Sentence (c) is ungrammatical, for modal verbs occupy the position of ASPP, they don't allow the affix on the main verb, aspect markers -le, -zhe and - guo are suffixes of verbs. Therefore, modal verbs cannot co-occur with aspect markers -le, -zhe and-guo. However, sentence (b) allows aspect marker -le to occur though ASPP is occupied by modal verbs. Why is sentence (b) grammatical? By comparing sentence (b) with sentence (c), we find that only modal verbs are different. Modal verbs keneng and yinggai are epistemic, while modal verbs keyi, neng, hui, and xiang are root modal verbs, that is to say, they are deontic or dynamic. So epistemic modal verbs can co-occur with aspect markers -le, -zhe and-guo, root modal verbs cannot. This suggests that only root (deontic and dynamic) modal verbs occupy the head of ASP and have complementary distribution with aspect markers -le, -zhe and -guo.

\section{Epistemic Modal Verbs as $C P$}

Now what's the position of epistemic modal verbs? The most compelling argument is that epistemic modal verbs must be higher than root (deontic and dynamic) modal verbs. The order of different modal verbs is epistemic $>$ deontic > dynamic. Deontic and dynamic modal verbs belong to root modal verbs, so epistemic modal verbs must occur before root modal verbs, the order of them cannot change, such as the following sentences:

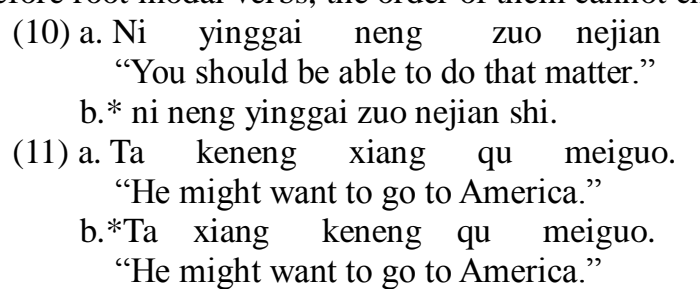

In sentence (10), yinggai has an epistemic interpretation; neng expresses a dynamic interpretation. In sentence (10a), yinggai occurs before neng, and it follows the rule of succession and the sentence is grammatical. In sentence (10b), neng occurs before yinggai, and it violates the order of succession and the sentence is ungrammatical. We can get the same conclusion in sentences (11). Therefore, epistemic modal verbs must occur before root (deontic and dynamic) modal verbs. That is to say, epistemic modal verbs are higher than ASPP.

If we assume that the higher level from which epistemic modal verbs operates is in fact in CP, and select IPs as their complements. There are two arguments to support our assumption that epistemic modal verbs are in CP. One is that epistemic modals are generally absent from nonassertive sentences. The other is that epistemic modals cannot be in the scope of negation. We will discuss them in detail in the following parts.

1. Nonassertive Contexts

Jackendof (1972) was perhaps one of the first to notice that epistemic modals do not occur in polarity questions, and Hermeren (1978) made a similar observation. McDowell (1987) has shown that the same is true for WH-questions, the epistemic reading is also not available when the modal occurs in an indirect question. Furthermore, Progovav (1988) shows that epistemic modals are also excluded from protasis of a conditional. We also find that it is true for Chinese epistemic modals. Consider the following sentences:

(12) a. Weishenme xiaoming neng qu canjia zhege huiyi?

"Why can xiaoming attend this meeting?"

b. *Weishenme xiaoming keneng qu canjia zhege huiyi?

"Why might xiaoming attend this meeting?"

(13) a. Ruguota neng zaodian chufa, ta jiuneng ganshang huoche.

"If he sets off early, he can catch the train."

b. *Ruguota keneng zaodian chufa, ta jiuneng ganshang huoche.

"If he sets off early, he can catch the train."

Since not only interrogatives but also conditionals are involved, all the above restrictions underline the fact that 
epistemic modals cannot occur in nonassertive contexts. In fact, we propose that epistemic modals must be in INFL at PF but undergo obligatory moving from INFL to COMP at LF. In sentence (12b), COMP is indexed by the WH-operator weishenme(why) at PF. When the epistemic modal verb moves at LF, it is contra-indexed with the WH-operator weishenme(why) and cannot antecedent govern its trace in INFL, which can account for the ill-formedness of (12b).

[cp [compi Weishenme ${ }_{i}$ keneng $_{j}\left[\right.$ IIP Xiaoming[ INFL $_{\mathrm{j}} \mathrm{t}_{\mathrm{j}}$ [ [vP qu canjia zhege huiyi $\left.\left.\left.\mathrm{t}_{\mathrm{i}}\right]\right]\right]$ ?

In sentence (12a), neng has a deontic interpretation, so it can occur in the WH- question. From the above sentences, we can conclude that WH-movement blocks the epistemic reading. The same proposal can account for the sentences (13).

2. Negation

The scopal relationship between modality and negation is controversial and has given rise to considerable discussions. It is clear that certain modals cannot be in the scope of negation. It has known for a long time that modal or evidential adverbs like probably, supposedly, evidently, obviously, etc, which we may assume to be specifiers of MepP, as suggested in Cinque (1999), cannot occur in the scope of negation (Jackendoff, 1972).

(14) a. John probably never ran so fast.

b. *Never did John probably run so fast.

The same scopal asymmetry also shows up in another well-known restriction: Modal/evidential adverbs neither have morphological nor constituent negation (Bellert, 1977)

(15)* Improbably/ * Impossibly John has gone home.

It is interesting to note that modal/evidential adjectives are free from this constraint when they occur in predicative function.

(16) It is improbable/ impossible that John has gone home.

The same observation obtains for Chinese. In sentences (17), hen keneng can occur before VP or CP, while bu keneng can only appear before VP, not CP, such as in sentences (18).

(17) a. Tamen lianggeren hen keneng hui zhenglun qilai.
They two person very might will argue asp
"It is possible that they will argue."
b. Hen keneng tamen lianggeren hui zhenglun qilai.
Very might they two persons will argue
"Probably the two persons will argue."
(18) a. Tamen lianggeren bu keneng hui zhenglun qilai.
They two persons not might will argue asp
"It is impossible that the two persons will argue."
b. *Bu keneng tamen liangeren hui zhenglun qilai.
Not might they two persons will argue
"*Improbably the two persons will argue."

The above sentences support the argument that epistemic modal verbs are in CP. This suggests that epistemic modality is not part of the proposition but takes entire proposition into its scope. The negative adverb $b u$ is part of the proposition. Therefore, in sentences (17), keneng has an epistemic interpretation, when it is modified by the degree of adverb hen; hen is the specifier of MepP. Hen keneng is still in CP, it can occur before VP or CP. When keneng is modified by negative adverb $b u$, the negative scope is the modal verb keneng, not the whole sentence, so when $b u$ keneng in sentence (18b) occur before the subject, that is to say, bu keneng takes the whole sentence as its complement, the sentence is unacceptable. At the same time, negative adverb is part of the proposition, while epistemic modality is not part of the proposition ${ }^{2}$. So bu keneng can not appear before subject. We can also explain the ungrammatical sentences (14b) and (15).

However, it is interesting to note that bu keneng can head the sentence in the following sentences. Sentence (19a) can be transformed into sentence (19b) and they express the same meaning. In fact, the structure of sentence (19a) is different from the structure of sentence (19b). In sentence (19b), bu keneng takes IP as it complement and it is ungrammatical, while bu keneng takes VP as its complement in sentence (19a) and it is grammatical. Therefore, bu keneng can only occur before VP not CP. The structure of sentence (19b) is like the structure of the above sentence (16). That is to say, when modal verbs occur in predicative function, they are free from this constraint. Therefore, sentence (19b) is grammatical. The following sentences again provide the additional support for the argument.

(19) a. Bu keneng shi xiaoming lai canjia zhege huiyi.

Not possible is xiaoming come attend this - CL meeting

"It is impossible that xiaoming attend this meeting."

b. Xiaoming lai canjia zhege huiyi shi bu keneng de. Xiaoming come attend this-CL meeting is not possible

${ }^{2}$ Examples from Rochette (1990:388f):

a. Probablement que marie viendra demain. Probablement Marie viendra-t-elle demain. b. When que is missing, complex inversion is possible, as Dubuisson and Goldsmith (1976) observe. This suggests that epistemic modality is not part of the proposition but takes the entire proposition into its scope. This again provides additional support for the association of epistemic modality with COMP. 
"It is impossible that xiaoming attend this meeting."

So far in this section, we have provided two arguments for the assumption that epistemic modal verbs are in CP. The first argument is that epistemic modals cannot occur in nonassertive contexts. The second is that epistemic modal verbs that are negated by negative adverbs cannot occur before subject.

\section{NEW PROPOSAL}

As we have argued in above section, root modal verbs are in ASPP, and they have complementary distribution with aspect markers; while epistemic modal verbs are in $\mathrm{CP}$, and they have complement distribution with nonassertive contexts. Though many linguists have reached agreement that epistemic and root modal verbs are merged at different levels, epistemic modals are merged somewhere within the IP level, and roots (deontic and dynamic), somewhere within the VP. They don't make the modal verbs related to ASP, accounting for the complementary distribution between modals and aspect and making the root into an aspect marker. This new proposal mentions this point and argues that root modal verbs are in ASPP and have complementary distribution with aspect markers; they take VP as their complements, while epistemic modal verbs are in CP and select IP as their complements; they have complementary distribution with nonassertive contexts. This new proposal can explain the following questions.

The first one is that why some modal verbs can co-occur with aspect markers, while others cannot. Consider the following sentences:

(20) a. Tamen keneng/yinggai ying-guo qiu.

"They might have won the ball."

b. *Tamen neng/keyi ying-guo qiu.

"*They can have won the ball."

In sentence (a), modal verbs keneng and yinggai have epistemic interpretations; they can co-occur with aspect marker -guo. In sentence (b), modal verbs neng and keyi have deontic interpretations; they cannot co-occur with aspect marker -guo. According to the new proposal, we know that epistemic modal verbs are in CP and select IP as their complements, root modal verbs are in ASPP and select VP as their complement, and they have complementary distribution with aspect markers.

In sentence (a), epistemic modal verb keneng occupies the position of CP and there are no root modal verbs or aspect marker zai that occupy the position of ASPP, so there is an empty Aspect node functioning as the head that licenses the corresponding affix on the main verb. This would be treated by making -le (-guo/-zhe) a base-generated verb affix, which moves at LF to the next upper functional head. Therefore, epistemic modal verb keneng can co-occur with aspect marker - guo, and we can explain the grammatical sentence (a).

In sentence (b), deontic modal verb neng occupies the position of ASPP, when aspect marker - guo moves at LF to the next upper functional head, the position has been occupied by deontic modal verb and there is no place for the aspect marker - guo to occupy. So we can explain the ungrammatical sentence (b).

The second is that why some modal verbs can occur in nonassertive context, while others cannot. The following sentences indicate that some modal verbs can co-occur with interrogative adverbial weishenme, while others cannot.

(21) a. Ren weishenme hui si?

"Why will people die?"

b.* Ren weishenme keneng si?

"Why might people die?"

In above sentences, modal verb hui in sentence (a) has deontic interpretation, while modal verb keneng expresses an epistemic interpretation. The above examples indicate that deontic modal verbs can co-occur with interrogative pronoun weishenme, that is to say, they can appear in nonassertive context; while epistemic modal verbs cannot. As for this point, we can use the new proposal to explain it.

As we have argued in above section, root modal verbs and aspect marker zai are the head of ASP, generating the AspP, with the VP in their scope, and root modal verbs have complementary distribution with aspect markers. In sentence (a), deontic modal verb hui occupies the position of ASPP, WH-operator weishenme occupies the position of the Spec of CP, they have their own proper positions and are not in conflict with each other. Therefore, sentence (a) is acceptable.

As is known in above section, epistemic modal verbs are in CP and select IP as their complement. In sentence (b), epistemic modal verb keneng occupies the position of COMP, while COMP is indexed by the WH-operator weishenme at PF. When the epistemic modal verb keneng moves at LF to COMP, it is contraindexed with the WH-operator and cannot antecedent govern its trace in INFL, which can account for the ill-formedness of (b).

The above questions in turn support our assumption that epistemic modal verbs are in $\mathrm{CP}$, while root modal verbs are in ASPP and have complementary distribution with aspect markers.

\section{Summary}

In this paper, we mainly discuss the syntactic structure of modal verbs. Based on the former studies, we make modal verbs related to aspect markers. By comparing modal verbs with aspect markers, we put forward a new proposal that root modal verbs originate in ASP, taking VP as their complement, and they have complementary distribution with 
aspect markers. We also claim that epistemic modal verbs are in CP, taking IP as their complement, and they have complementary distribution with nonassertive contexts. We provide two arguments to support our assumption. The two arguments are the inability of epistemic modal verbs to occur in nonassertive contexts and the asymmetry of negation of modal verbs. We carry out the new established proposal to solve some problems, such as the compatibility between epistemic modal verbs and aspect markers and incompatibility between epistemic modal verbs and nonassertive contexts. This new established proposal can adequately account for not only the succession of modal verbs but also some controversial issues.

\section{REFERENCES}

[1] Bellert, Irena. (1997). On Semantic and Distributional Properties of Sentencial Adverbs. Linguistics Inquiry, 8:2, $337-351$.

[2] Brennan, Virginia. M. (1993). Root and Epistemic Modal Auxiliary Verb. [Ph.D.Diss.], University of Massachusetts.

[3] Cinque, Gugliemo. (1999). Adverbs and Functional Heads: A Cross-Linguistic Perspective. Oxford: Oxford University Press.

[4] Cormack, Annabel and Neil Smith. (1997). Checking Features and Split Signs. University College London Working Papers in Linguistics, 9: 223-252.

[5] Cormack, Annabel and Neil Smith. (1998). Negation, Polarity and V Position in English. University College London Working Papers in Linguistics, 10: 285-322.

[6] Dubuisson, C. and J. Goldsmith. (1976). A Propos de 1's Inversion du Clitique Sujet en Francais. NELS6, Montreal Working Papers in Linguistics6, 103-112.

[7] Hermeren, L. (1978). On Modality in English. Lund: Gleerup.

[8] Jackendoff, Ray. (1972). Semantic Interpretation in Generative Grammar. Cambridge, MA: MIT Press.

[9] McDowell, Joyce. (1987). Assertion and Modality. [Ph. D. Diss.], University of Southern California.

[10] Palmer, F. R. (2001). Mood and modality (2nd ed). Cambridge: Cambridge University Press.

[11] Picallo, C. (1990). Modal verbs in Catalan. NLLT 8, 285-312.

[12] Progovav, Ljiljana. (1988). A Binding Approach to Polarity Sensitivity. [Ph.D.Diss.], University of Southern California.

[13] Rochette, Ann. (1990). The Selectional Properties of Adverbs. CLS26, 379-391.

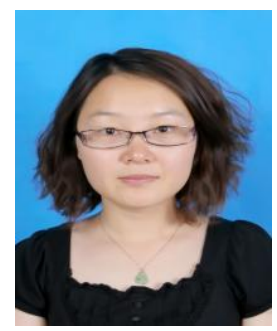

Jinging Cui, born in China on July, 1979, graduated from Foreign Language Department of Qufu Normal University in 2003, getting the Bachelor Degree, after that, she continued her further study on foreign linguistics and applied linguistics in Foreign language Department of Hunan University, obtaining the Master Degree in 2006.

After her graduation in 2006, she has been working in the School of Applied English Studies, Shandong University of Finance \& Economics, Jinan, China, teaching Linguistics, College English, Business English \& so on. She has published several papers on linguistics in journals. One of the papers was awarded the 2010 excellent achievements in scientific research by the Shandong Provincial Foreign Linguistics Association. 